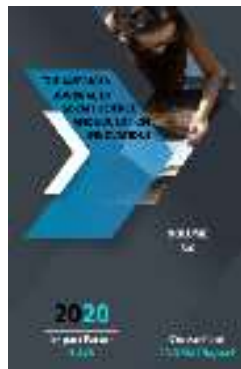

Journal Website: http://usajournalshub.c om/index,php/tajssei

Copyright: Original content from this work may be used under the terms of the creative commons attributes 4.0 licence.

\section{Development Of Students' Descriptive Competencies In Pencil Drawing Practice}

\author{
Botir Boltabaevich Baymetov \\ Professor, Member Of The Union Of Artists Of Uzbekistan, Department Of Fine Arts, Chirchik \\ State Pedagogical Institute, Uzbekistan
}

Muhiddin Shokirjon Ogli Sharipjonov

PhD Student, Namangan State University, Uzbekistan

\title{
ABSTRACT
}

This article discusses the issues of improving the competence of the future in the professional training of specialists in the field of fine arts by teaching the rules of practical exercises in the field of drawing. Drawing a short sketch from the imagination, depending on the nature in the formation of students' competencies in practical training, which is the basis for developing the student's ability to quickly see and understand nature.

\section{KEYWORDS}

Competence, practical exercises, fine arts, pencil, composition, fine arts, nature, perception, sketching.

\section{INTRODUCTION}

Practical exercises are the main criterion in the training of future specialists in the fine arts. The main of them are practical exercises in the field of pencil drawing, the implementation of practical work in the educational process is carried out in stages by the method of depiction "From general to specific and from specific to general", which is one of the foundations of fine arts.
It is designed to draw a brief sketch of its peculiarities, depending on the nature, in the formation of competencies of students in practical classes. It is also designed to help the student develop the ability to see and comprehend nature quickly. 


\section{THE MAIN FINDINGS AND RESULTS}

Observation, perception, and sketching depiction often occur simultaneously. It is important to identify the following six types of methods used in drawing Sketches to develop drawing skills in practical training.

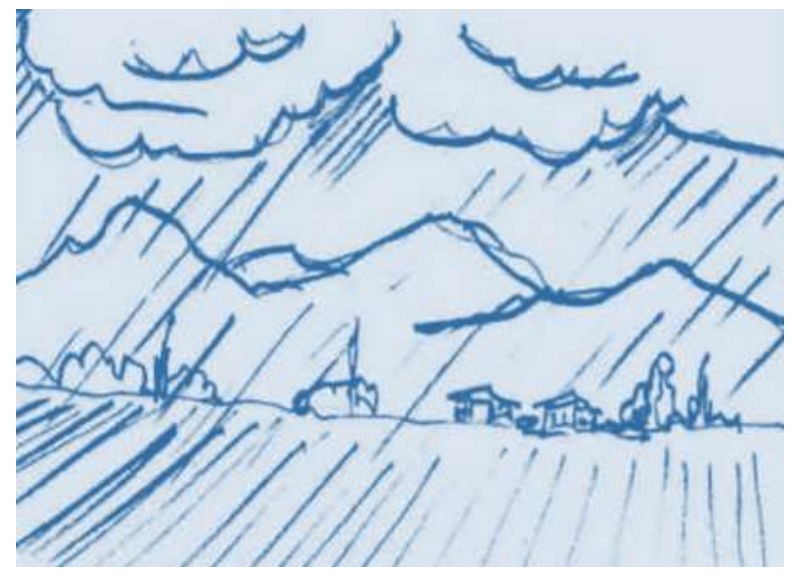

- Sketches performed directly from beginning to end, observing nature.

- $\quad$ Sketches depicted in the combination method (first by nature, then by nature - by memory).

- Sketches ctures that are executed only from memory, that is, after some time after observation, when the ability to see in the mind is strengthened.

- Sketches of perceptions related to the ability to revive perceptions of certain objects, living objects, and surrounding phenomena previously perceived in the human mind.

- Sketches performed by a complex method, ie using all the above methods of work, including imaginary methods.

- Imagination - drawing generalized sketches of an image on the basis of any creative idea or artistic image, theme, plot, etc., animating and reconstructing their own ideas about objects and events.

When making sketches in practical exercises, the condition, number, and complexity of the object being depicted at the same time (at rest or in motion) are, in other words, from the content of the sketch itself, as well as the objective conditions encountered in practice.

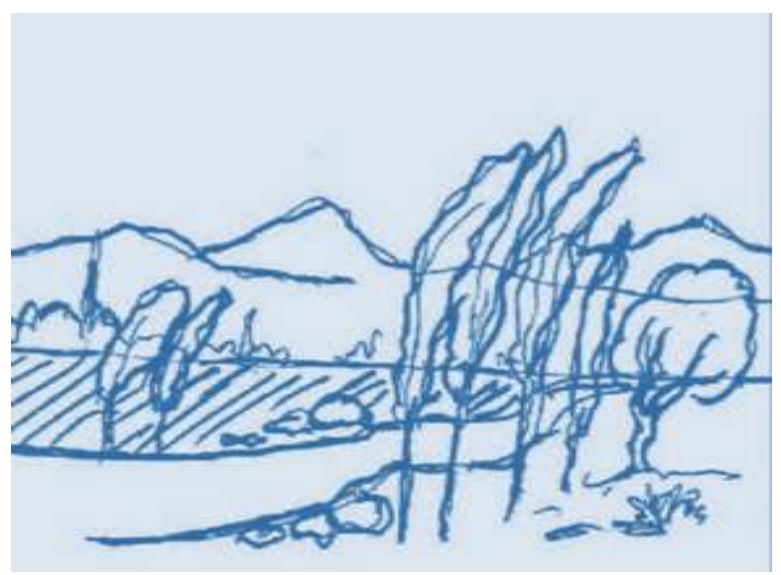

One of these conditions is whether or not time is limited for nature observation and sketch execution. This in turn depends on the immobility of nature or the degree of excitation (speed of movement). In other words, the method of sketching is primarily influenced by two factors: time and the state of nature.

In addition to these interrelated factors, the performer and his performance (hence the character and quality of the image in the sketch) are also affected by external objective

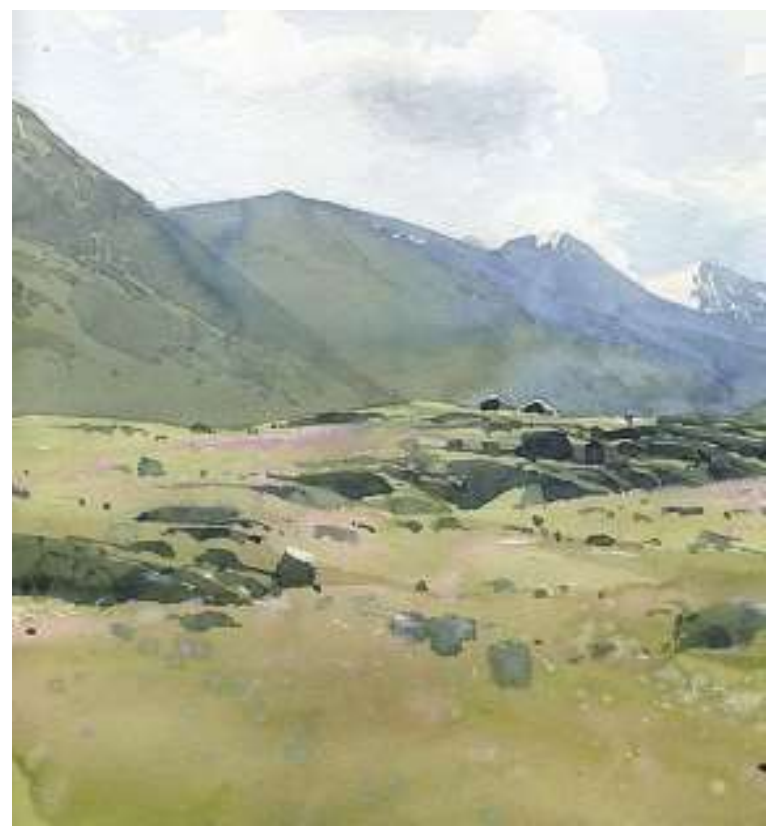


conditions to which the painter must adapt (rural, mountain, urban landscapes, etc.) Figure 1,2). Drawing a sketch from observation of nature can be done from the beginning to the end only if there is only one condition, that is, when nature is completely motionless. Such nature may be primarily an inanimate object (e.g., fruit, flower, tree, rock, and some landscape species) (Fig. 3). The artist works relatively calmly, as the purpose of the sketch is to reflect an incompletely generalized view of nature. If the goal has been achieved and nature is not yet moving, then it is possible to move from the sketch to the line (plate). It is even possible to make more detailed sketches of some pieces in addition to the edge of the paper.

If the immobility of nature is conditional and accidental, in some cases it is temporary, that is, when nature changes its position, facial expressions, gestures at any time unknown to the artist, and even disappears completely from view, then work on drawing sketches of nature the character changes drastically. This can happen when you accidentally draw a sketch of a living model (sitting or standing in a park bench, or a dog lying quietly suddenly starts barking, etc.).

When doing a sketch of the landscape - no need to make sure that the weather or lighting conditions do not change, the wind can stop, the flat water surface can be rippled by waves, the sky can suddenly be covered by black clouds).

In nature, living nature does not stand in the same rhythm as in the artist's workshop or as a classroom learning attribute. It goes on in his life, and his natural, temporary immobility can be immediate, and sometimes unexpected, the opposite.

It should be noted that it is precisely such immobile conditions of a living model, i.e. a calm, serene appearance, that are most valuable to the observer's observant eyes. On the contrary, a living model that stands specifically in the same state always loses its expressiveness, because in any case there is artificiality. On top of that, the same starer looking at you eventually gets tired which inevitably affects his character.

That is why the artist must always be ready to accurately depict a living model in a sketch.

It will be necessary to make efficient use of every minute, even every second, to observe and complete the sketch during the time available for work. It is no coincidence, therefore, that the word "sketch" has synonyms such as "short," "very fast," "at a glance," "at lightning speed," and "in an instant."

The specific purpose of sketching is to instantly display the result of the observation on paper. True, if there is enough time, then it can not even be called a sketch.

In classroom classes, especially in the early stages of teaching sketching, students always have enough time for both observation and drawing.

But working on a sketch outside the classroom can mean a sudden interruption in both observation and drawing at the same time. Sometimes the artist tries to achieve a goal faster, to immediately reflect the typical and characteristic features of nature. The tracking time coincides with the execution time. In such a case, with the perception of seeing nature, the execution is sharpened. That is, without distraction, without giving in to small, secondary details, one immediately tries to grasp the essential aspects of the subject, using the simplest means to a minimum. 
First of all, with a few reliable lines, it is necessary to determine the location and size of the future image - its outline (construction). It is necessary to take down the whole mass of nature, taking into account the main parts, and their movements.

When you start drawing a sketch, it seems to stop for a while, but if the logical sequence in the work is followed, everything will fall into place. If nature maintains its immovable state, it is necessary to immediately proceed to the elaboration of the set points, to grasp more quickly the most basic, characteristic features.

As nature begins to move, as it changes its position, you have to use your ability to see from memory to complete this sketch.

Advanced vision (memory ability) is a great help in filling in the details of what was previously seen.

Starting with nature and then finishing in memory without his participation, the sketch is considered "Combined".

The reduction in observation time also complicates working on the sketch and requires a great deal of memory. Such cases are very common in practice.

It is much more difficult to instantly reflect a state of nature that is in constant, constant motion. At such a time, it is important to grasp it all at once and immediately, without delay, write down what is sealed in your memory. That's when the memory-sealed look doesn't lose its "novelty." An example of this is an athlete running fast in front of you. Such a task is possible in practice.

To do this, you need to quickly grasp the expression in motion at a glance (for example, the body of a running athlete, the movement of the legs, head and arms. Fig. 4) But at this point it is important not to forget to put together the sketched lines, that is, to coordinate them in terms of composition.

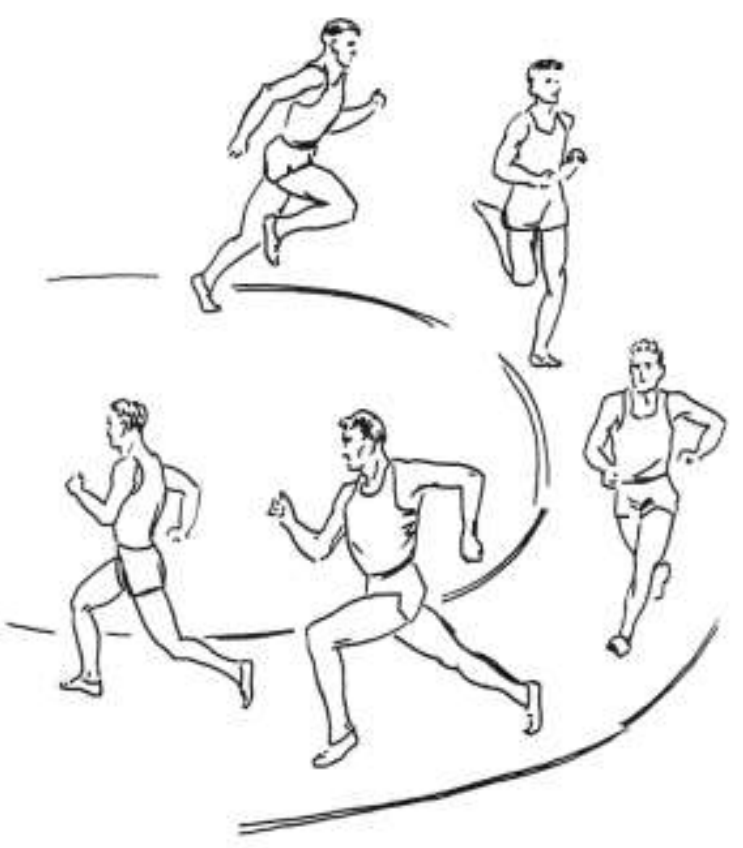

If the ability to see is strong, it is possible to achieve a very short and sometimes generalized depiction of forms that are imprinted in memory in a second. A sketch executed in this way is like a memory stamped on paper.

Corrections and additions to such sketches are made only by repeating the action of the same athlete (almost the same action), by memorizing it again.

The need to work on a sketch, relying only on the ability to store it in visual memory, arises only in situations where external conditions allow observation. For example: a portrait of a passenger sitting in front of you in a vehicle looks like the character of the picture you are imagining, and the image you have been looking for for a long time comes out in front of you. It is impossible to draw it out of nature, for it can take away its gaze, turn its head, or change its appearance, and so on. 
You have to choose a way to solve the tasks set before you, which uses your visual ability: you observe, study it without noticing your nature, try to remember the characteristic features of the character (especially the distinguishing features in it). The passenger fell at his station. Then immediately, no later than you take your pocket album (otherwise it may fade from your memory) and draw a sketch from memory as you remember that passenger status.

There are many such examples. But in order for an artist to develop visual memory, the person in motion needs to draw sketches, especially looking at a group of people whose character and speed of movement are different. For example, drawing sketches depending on the athletes involved in sports such as arm wrestling, football, athletics, gymnastics, volleyball will be a big factor in the development of skills such as plastic anatomy, linear constructive drawing.

It should be borne in mind that the quality of the image to be remembered as a result of observation and its sealing in memory are affected by many causes and circumstances. Especially in a partial case, what has been carefully observed in a schematic view of a line drawn from nature to paper, and learned in the process of direct depiction, is well preserved in memory, what is mechanically copied without analyzing the image is usually not stored in memory for long.

Drawing a sketch in the imagination is not related to direct observation of nature. It is performed only on the basis of previously perceived events in the world of the subject and sealed in the mind. Imagination is more general than perception. They have less detail and only reflect the basic features of the object and events. That is why the sketch drawn in the imagination is close to the phrase "out of itself" and is said to describe any object and event by imagining it, adding and supplementing some aspects of it. It is different from a sketch drawn directly on nature.

The person who draws in the imagination is free from factors such as the time and state of nature that surrounds him. He is calm, all his attention must be drawn to the sketches, relying on his previous imagination. It is also important to ensure that the image is realized in a realistic way.

The simplest task is to solve the problem of imagining a simple chair on the floor, it must be able to remember its construction and the ratio of the basic dimensions, and to imagine its imaginatively practical state.5 Fig.

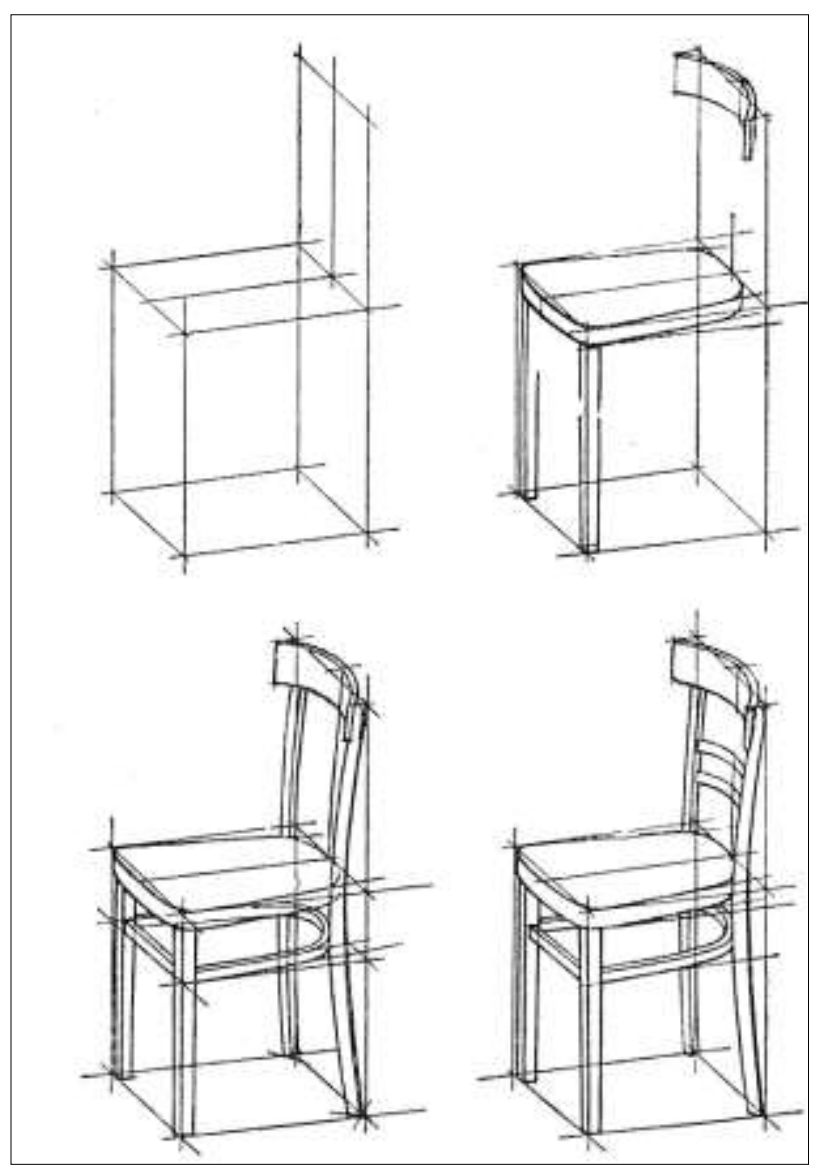

So what does the same chair look like from 
above and below? The answer to a self-asked question poses some difficulty at first, it is necessary to master these difficulties before grabbing a pencil and starting to draw. The more complex the construction of an object shape, the more difficult it is to draw it out of "out of itself" imagination.

The artist is faced with the task of restoring in his mind (imagination) a wide-ranging image of the object. Such a restoration process is of synthetic importance, it includes not only the idea of the shape of the object, but also other latitudinal proportions such as its construction, its relative size, proportions, its direction and speed of motion.

For example, if we draw a sketch of a complex living form without human nature, such as a human figure, and the nature of this image is in a fast motion, a turn, or in another position (say, an athlete trying to cross an obstacle with an anchor), the task is much more complicated.

Before performing a sketch, we need to imagine the image of the image in memory, its construction, and in general, what size this shape will occupy on paper from a certain point of view. Only then, after calling out the plastic anatomy of man for help in memory, "out of ourselves" on a sheet of paper, marking the scheme of movement, plus the ratio of torso, head, limbs, their size, the proportions of contraction during movement, the state of illumination you can start drawing.

\section{CONCLUSION}

The above examples are not in vain. The first example shows the simplest way to draw a sketch in the imagination. If we compare it with the method of drawing a sketch from nature based on continuous active display and analysis of the form depicted, it becomes clear that the sketch drawn in the imagination is based on the restoration of a previously known and preserved form in memory.
Exercises made from complex parts of the human body, such as the bones of the head, arms, and soles of the feet, also give good results. The ability to freely and expressively "take out" (without nature) the human body in any position and move quickly can only be achieved by sketching "from nature" and "from memory" as a result of a good knowledge of human plastic anatomy, primarily skeletal structure and skeletal mechanism movements occurs as a result of more exercise. Educational sketches made in the imagination have a great influence on the development of a person's ability to depict different situations, that is, motionless and moving states.

In order to better understand the in-depth study of the human body in practice, it is enough to analyze many of the images worked by great artists who are famous in history and to look carefully at the appearances of human figures. They are all pictures drawn "out of their minds" in the imagination.

A lot of space is given to auxiliary exercises to test the mastery of the materials covered in the ongoing learning tasks to teach practical drawing to be done in the imagination.

Such sketch practical drawing exercises on imagination help to develop important skills in drawing confidently in students. In particular, this demonstrates its positive results in improving its descriptive competencies through hands-on training in performing tasks with a clear purpose.

\section{REFERENCES}

1. Baymetov B. "Pencil drawing". Textbook part 1. Tashkent: "Music". 2006.

2. Baymetov B. "Pencil drawing". Study guide. Tashkent: "ILM ziyo" 2007.

3. Baymetov B.B. Textbook "Sculpture and Plastic Anatomy". Tashkent: Finance and Economics. 2011. 
The American Journal of Social Science and Education Innovations (ISSN - 2689-100x)

Published: August 25, 2020 | Pages: 261-267

Doi: https://doi.org/10.37547/tajssei/Volume02Issue08-42

4. Baymetov Botir Boltaboevich. Formation of the skills of portraying the future teacher of fine arts in pencil drawing. ACADEMICIA An International Multi disciplinary Research Journal (Double Blind Refereed \& Reviewed International Journal) -p. 1122

5. Kuzin V.S. Sketches. Textbook for students of higher educational institutions. Moscow: 2004.

6. Lee N.G. "Fundamentals of educational academic drawing" Moscow: "Eksmo". 2005.

7. $\quad$ Reed W. Figure. (Per. From English; LLC “Potpurri”, Minsk. 2000. -p. 144. With ill. (Series of drawing school)

8. Rostovtsev N.N. Academic drawing. Moscow: "Education", 1985. 